\title{
Application of histochemistry AgNORs in diagnosing benign lesion, premalignant and malignant prostate tissue
}

\author{
Lidya Imelda Laksmi ${ }^{a}$, Fauriski Febrian Prapiskab, T. Ibnu Alferraly,"* \\ ${ }^{a}$ Department of Anatomical Pathology, Universitas Sumatera Utara, Indonesian Association of Pathologist, Medan, Indonesia \\ lidya.imelda@usu.ac.id \\ bepartment of Surgical Urology, Universitas Sumatera Utara, Indonesian Urological Association, Medan, Indonesia \\ fauriski@gmail.com \\ cDepartment of Anatomical Pathology, Universitas Sumatera Utara, Indonesian Association of Pathologist, Medan, Indonesia \\ tia_mdn2004@yahoo.com
}

\begin{abstract}
Objective: Argyrophilic nucleolar organizer regions (AgNORs) count has been suggested as an objective method in differentiating of various non neoplastic lesions of the prostate. Material and Methods: This study was done on archival paraffin block consisting of 6 cases of each, benign, premalignant, and malignant lesions of the prostate. All specimens were studied and evaluated with Haematoxylyn and Eosin followed by AgNORs histochemistry staining and its expression was determined by counting AgNORs dot per nuclei in 100 nuclei using a 100x oil immersion lens. Results: The results showed a linear increasing trend of mean $\mathrm{mAgNOR}$ count according to prostatic lesion (benign to malignant). However, this is not statistically significance as the p-value $>0,05$ (pvalue $=0,516$ ). Conclusion: Based on this study, AgNOR cannot be use to determine prostatic lesion behavior. Futher study with larger samples should be done to get significant result.
\end{abstract}

Keywords: benign, premalignant, malignant, prostate, AgNORs

\section{INTRODUCTION}

The incidence of prostate cancer in Asia about 7.2 per 100.000 men each year. In Indonesia, number of prostate cancer in three medical center education hospital (Jakarta, Surabaya and Bandung) during the last 8 years is 1,102 patients with median aged 67.18 years [1]. Meanwhile, the incidence rate of prostate cancer in Medan, North Sumatera on 2014-2016 years period are in range 305 cases [2]. The important thing in success handling of prostate cancer was early detection in diagnosis. In USA over $90 \%$ of prostate cancer is define in early staging, with near 100\% five years survival rate. Unfortunately, in Indonesia most of the patients was already diagnosis in the late staging. The Indonesian Society of Urologic Oncology (ISUO) 2011 issued that on 2006 - 2010 years period there is 971 patients of prostate cancer and 50,5\% of them was already diagnosis is late staging (stage 4) [1].

On routine examination in staining Haematoxylin and Eosin sometimes have difficulties to identified benign, premalignant and malignant lesions of the prostate. The important thing to diagnosis as malignant lesion is the loss of basal cell layer, while in benign lesion must have the presence of basal cell layer. Immunohistochemistry (IHC) staining can help to identified basal cell layers with: high molecular weight cytokeratin (HMWCK) or p63 [3]. Thus far IHC needed high cost facilities to use as a routine diagnosis in prostate lesion. From this study we want to evaluate, is AgNOR can be an addition examination as a routine staining together with $\mathrm{HE}$ to help determine benign, premalignant and malignant prostate lesions as a IHC substitute?

\section{MATERIAL AND METHOD}

This study was done on archival parrafin block consisting of 6 cases of each, benign, premalignant, and malignant lesions of the prostate. The parrafin block sectioning at $3 \mu \mathrm{m}$ thickness to done routine staining Haematoxylin and eosin to confirm the lesions, benign, premalignant, and malignant lesions. The next steps is silver staining of nucleolar organizer region (AgNORs).

The procedure AgNOR stain and AgNOR counts

Three-micron unstained section parrafin block was deparaffinized in xylene (three parts in 3 minutes each part). 
Rehydration in several ethanol (100\% in 2 minutes, $95 \%$ in 2 minutes and $70 \%$ in 1 minute) and then rinsed with tap water in 1 minute. The sections were then immersion the preparations in the sodium citrate buffer and then incubation in an autoclave at a temperature of $120^{\circ} \mathrm{C}$ (pressure from 1.1 to 1.2 bar) for 20 minutes and then let the preparation cooled in temperature $37^{\circ}$ C. Immersion the preparations into a silver solution consisting of: 1 part $2 \%$ gelatin volume in formic acid $1 \%$ and 2 parts of silver nitrate solution $25 \%$, in temperature $37^{\circ} \mathrm{C}$ for 11 minutes. The next step is, stop the reaction by washing the slide preparations using the tap water to remove the non-specific silver precipitate. Dehydrated through increasing grade of ethanol $(50 \%, 70 \%, 95 \%)$, cleared in xylene and cover slipped $[4,5,6,7]$

AgNOR stained section was examined under the light microscope (Olympus CX 22). AgNOR counting was performed under 100x using oil immersion. The AgNOR were visualized as brown black discrete dots of variable size within the nuclei. The count was the mean number of AgNOR in 100 tumour nuclei (mAgNOR).

\section{RESUlts}

The results showed a linear increasing trend of mean mAgNOR count according to prostatic lesion (benign to malignant. However, this is not statistically significance as the p-value $>0,05$ (p-value $=0,516)$.

Study of mAgNOR

\begin{tabular}{|l|c|c|c|}
\hline $\begin{array}{l}\text { Prostatic } \\
\text { lesion }\end{array}$ & $\mathrm{N}$ & Mean & SD \\
\hline Benign & 6 & 2.835 & 0.80815 \\
\hline Premalignant & 6 & 3.1683 & 1.27969 \\
\hline Malignant & 6 & 3.5767 & 1.13978 \\
\hline
\end{tabular}

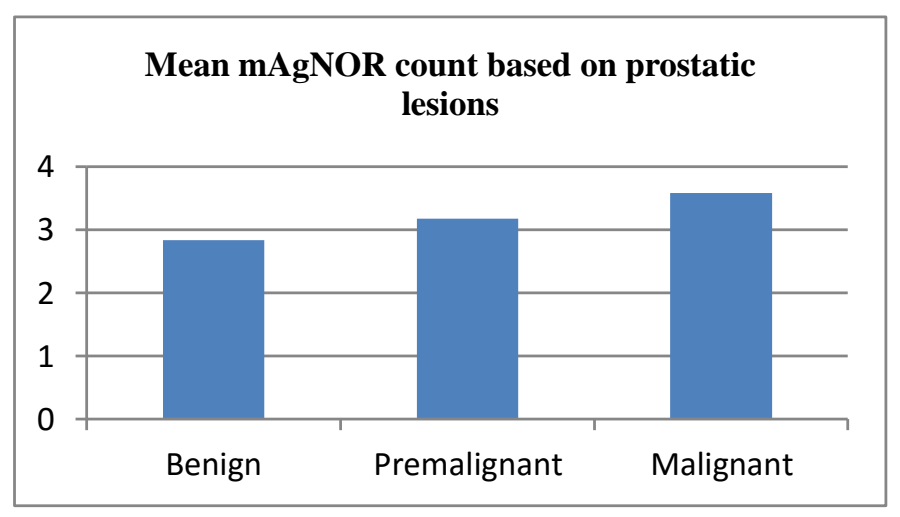

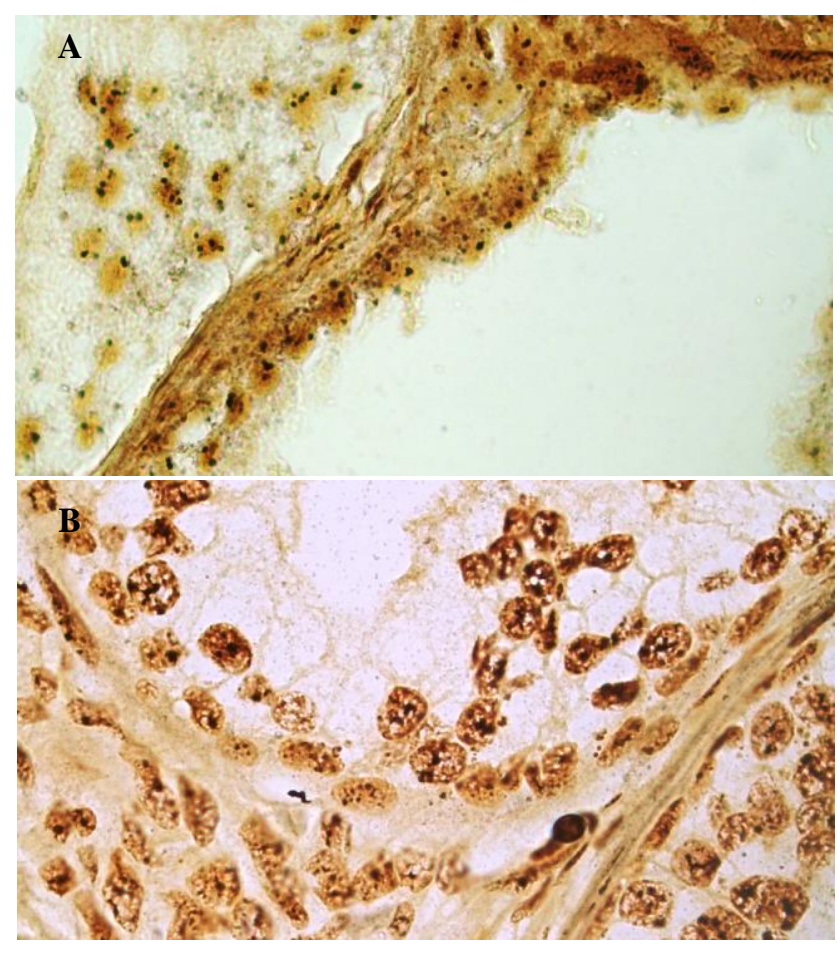

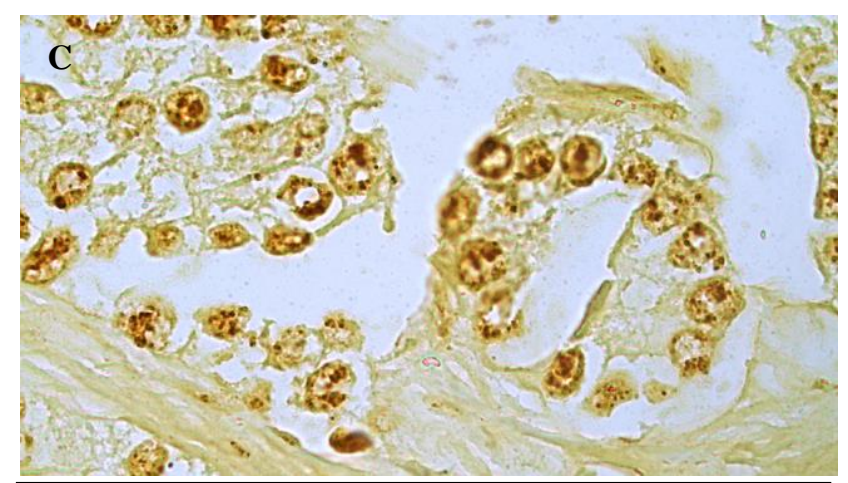

Figure showing AgNOR dots in the nuclei (x100 oil immersion):

A. Benign Prostatic Hyperplasia (Benign lesion)

B. Prostatic Intraepithelial Lesion (Premalignant lesion)

C. Adenocarcinoma (Malignant lesion)

\section{CONCLUSION}

Based on this study, AgNOR can not be use to determine prostatic lesion behaviour. Futher study with larger samples should be done to get significant result.

\section{REFERENCES}

[1] Indonesia Society of Urologic Oncology ISUO) meeting 2011. Unpublished data

[2] Data kanker Ikatan Ahli Patologi Indonesia cabang Medan 2017 
[3] Zhou M, Netto GJ, Epstein JI. Neoplastic disease of the prostate in Uropathology. Philadelphia. Elsevier 2012. p: 51-125

[4] Cancer Chemoprevention Research Center Fakultas Farmasi UGM.

[5] AgNOR counting in benign naevi and malignant melanoma. Journal of Pathology 1991; 163: 239-44
[6] Crocker J, David A, Boldy R, Egan MJ. How Should We Count AgNORs? Proposals for a standardized approach. Journal of Pathology 1989:158:185-88.

[7] Elangovan T, Mani NJ, Malathi N. Argyrophilic nucleolar organizer regions (AgNORs) in inflammatory, premalignant and malignant oral lesions: a quantitative and qualitative assessment. Indian J Dent Res 2008; 19(2):14146 